\title{
Team-Based Knowledge Sharing: Learning Through Complex Work Challenges
}

\author{
Roland Yeo, Saudi Aramco, Saudi Arabia \\ John Stubbs, Saudi Aramco, Saudi Arabia \\ Martin Barrett, Saudi Aramco, Saudi Arabia
}

\begin{abstract}
This paper explores a team-based knowledge sharing framework as a structured approach to addressing complex work-related challenges through the sharing of knowledge drawn from concrete experiences. Knowledge sharing is constructed through individual narratives that serve as the basis for collective sensemaking. In turn, interpretation of the problem at hand and articulation of related past experiences help develop reflective inquiry and dynamic feedback increasing team learning. When individuals select their frames of references to construct their narratives, they also unlock their tacit knowledge about past successful experiences or practices. Through collective sensemaking, team members develop critical change behaviours that lead to knowledge experimentation modifying their action patterns. Through an exploratory research design involving qualitative feedback analysis, semi-structured interviewing, and ethnographic participation in a Saudi Arabian multinational company, the study found that the framework promotes team learning in both formal and informal contexts. Not only do individuals begin to view organizational change differently, they also engage more actively in people conversations, collaboration, empowerment, and decision making resulting in specific organizational outcomes. The paper offers implications for human resource development (HRD) practice and research.
\end{abstract}

\section{Introduction}

Current turbulent times require that organizations remain agile and adaptive in sustaining their competitive advantage. Being agile and adaptive is challenging for organizations seeking change. In order to survive, organizations need to have the ability to learn in order to improve their performance through critical knowledge and insight (Fiol and Lyles, 1985). However, organizations cannot learn on their own; their ability to learn is contingent upon their teams' ability to learn (Edmondson, 2002). Teams are therefore expected to develop knowledge and skills that can be translated into practice within and across contexts, such as cross-functional and crossborder teams (Argote, 1999). Traditionally, teams have been conceptualized as work groups that share common objectives to accomplish specific tasks, including product development, sales, and service delivery teams (Hackman, 1987). In more recent literature, cross-boundary teams have been explored in the context of interdependent task structures requiring complex learning and coordination for accomplishing multilevel tasks (Schippers, Edmondson, and West, 2014). As team structure and composition become less permanent, teams also function in more resilient ways as they seek alternative means of learning through knowledge utilization (Bresman and Zellmer-Bruhn, 2013).

In this paper, we will focus on the implementation of a team-based knowledge sharing framework in Saudi Aramco, a large multinational company based in Dhahran, the eastern province of Saudi Arabia. In 2020, Saudi Aramco's strategic intent is to be the world's leading integrated energy and chemical company. This will be achieved by maximizing value creation, 
facilitating the sustainable expansion of Saudi Arabia's economy, and enabling a vibrant Saudi energy sector. To achieve this ambitious vision, the company has implemented the Accelerated Transformation Program (ATP). The ATP is a journey of transformation and renewal with the company's workforce playing a critical role in its success. Against the backdrop of the ATP, the company's workforce is undergoing unprecedented growth and change. Generation Y employees are replacing a highly experienced generation of older employees. As the ATP continues to be implemented, knowledge sharing is increasingly recognized as an important vehicle supporting company goals. The implementation of team-based knowledge sharing offers Saudi Aramco and its employees a forum for the exchange of knowledge and skills across generations, nationalities, and fields of work.

\section{Purpose statement}

Although team learning processes are related to knowledge acquisition and transfer to some extent, theoretical linkages between knowledge utilization and team learning have not been firmly established. In some studies, knowledge is viewed as a resource to improve team communication and coordination in order to accomplish certain tasks (e.g. Sole and Edmondson, 2002). In other studies, knowledge is associated with transactive memory systems where shared knowledge is embedded in the "minds" of teams to master particular tasks (e.g. Ren, Carley and Argote, 2006). This perspective is built on the assumption that knowledge does demonstrate unique properties and can therefore be specialized. Because contexts can shape learning, the way knowledge is shared and used in practice within and across teams could offer a different understanding of team learning. In this study, we explored team learning from the knowledge utilization perspective in Saudi Aramco. Through a longitudinal study, we examined how ten teams across six business areas with over 120 members engaged in knowledge sharing. These teams are structured and organized around the mechanisms of a team-based knowledge sharing framework. To guide the purpose of inquiry for this study, we raise the following research question: How is learning perceived as occurring through team-based knowledge sharing in Saudi Aramco?

\section{Context of the study}

Saudi Aramco's strategic 2020 vision is to increase its organizational learning capacity by unleashing human potential through four critical change behaviours: people conversations, collaboration, empowerment, and decision making. The behaviours were identified following a comprehensive study led by both internal and external experts, and have been shown to support and enable complex change in global organizations. Team-based knowledge sharing builds on the behavioural programme to help the company achieve its long-term strategy. In the context of a rapidly changing workforce, there is urgency for retiring employees to share their tacit knowledge with other employees before they leave the organization. Demographic shifts in the workforce also offer the opportunity for team-based knowledge sharing as a cross-generational and cross-occupational learning interface. The aim is to bridge generational gaps by engaging employees in these critical behaviours. Each of the four behaviours is governed by five corporate values: excellence, accountability, integrity, citizenship, and safety. The strategic vision is further driven by the organization's ATP aimed at leveraging its human capital to develop an agile workforce through a series of HRD interventions, including talent development and employee engagement. In cultivating a culture of learning and change, Saudi Aramco has engaged in team-based knowledge sharing since 2012. The aim is to develop a network of learning and practices across all levels, increasing the employees' capacity to learn continuously, rapidly, and adaptively. 
Team-based knowledge sharing allows employees to regularly meet together on a volunteer basis in small groups to share individual "best practices" and lessons learned, which are driven by complex and urgent work challenges for which there are no easy solutions. The process of knowledge sharing is facilitated by individual storytelling of direct experiences related to a particular work-related issue. Personal narratives form the core of knowledge interpretation and exploration based on the intersection of individual experiences which may or may not be familiar to members of the same team. The Saudi Aramco framework is built on a structured approach to knowledge sharing largely facilitated by a team leader or coordinator. It works primarily by means of face-to-face interaction in teams of no more than 12 members each in order to take learning to a much deeper and reflective level.

This article will provide the theoretical underpinnings of the framework, describe its practical implementation, and highlight its organizational outcomes. It will also outline some limitations to the study, highlight its implications for HRD, and note some suggestions for future research.

\section{A Team-Based Knowledge Sharing Framework}

Based on theoretical and empirical research (Yeo, 2006; Yeo and Marquardt, 2015), the framework is a unique approach to learning in that it is both a structured and spontaneous knowledge sharing process. As a continuous process of learning and knowledge experimentation, the framework operates by means of a prior learning (input), during learning (process), and post learning (output) continuum driven by a work-related problem, referred to as a "challenge statement" (see Fig. 1).

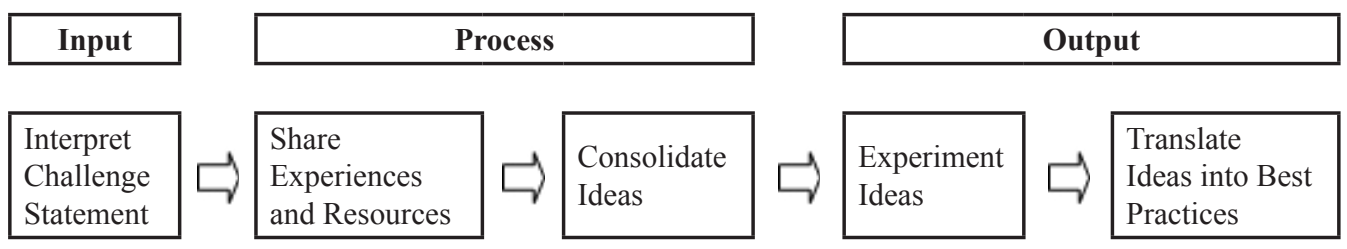

Fig. 1: Knowledge sharing framework in practice

As a process-driven framework, it is built on an integrative theoretical perspective based on David Kolb's (1984) experiential learning, Reg Revans' (1982) action learning, and Chris Argyris' (1982) theory of action. It promotes reflective practice (Schön, 1983) where individuals engage in cognitive participation through reflection, feedback, and dialogue not only to question assumptions but also to challenge the coproduction of actions that constitute practice affecting organizational learning. Knowledge sharing teams function in many respects like action learning sets where people gather in small groups voluntarily to share ideas with each other without the need of an expert. Revans referred to such groups as "comrades in adversity" (Cunningham, 2003: 4) as they learned from each other's experience. The underlying premise is that groups have the ability to awaken their quest for new knowledge by questioning their own assumptions, practices, and routines. Questioning allows group members to create and modify their frames of references as they make sense of their existing conditions by drawing on their past experiences (Fox, 1997). In other words, team-based knowledge sharing looks beyond causality and seeks to disintegrate complex problems to provide opportunities for members to engage in dialogue, feedback, and reflection as a collaborative inquiry (Marquardt, 2011). 
The learning of teams begins when members construct meanings around their surroundings to help them make sense of and reflect on specific organizational challenges for subsequent action-taking (Weick, 1995). Self-reflection is further supported by socio-cognitive inquiry (group reflection) where team members relate past concrete experiences to their perceived and lived experiences based on the shared understanding of existing challenges (Mezirow, 1990). Learning deepens through double feedback loops and reflexive understanding of the internal and external environment where team members formulate individual conceptual schemas for further experimentation (Simpson, French and Vince, 2000). With reference to Figure 1, doubleloop learning occurs in the "process" stage between "sharing of experiences and resources" and "consolidation of ideas", during which ideas and assumptions are challenged through discursive questioning and feedback (Argyris, 1982). Interactions in feedback giving help members become more aware of their internal maps, changing the manner in which they view particular work challenges. When ideas are consolidated, the team then moves towards idea experimentation by developing appropriate actions to change existing conditions (Coghlan and Coughlan, 2015; Kolb, 1984).

\begin{tabular}{|c|c|c|}
\hline Dimensions & Team-Based Knowledge Sharing & Action Learning \\
\hline $\begin{array}{l}\text { Enablers of } \\
\text { Learning }\end{array}$ & $\begin{array}{l}\text { Driven by specific challenge statements } \\
\text { agreed by members as a stimulus for } \\
\text { knowledge transfer. } \\
\text { - Questioning and feedback. } \\
\text { Appropriate inquiry and motivation of } \\
\text { volunteer members. }\end{array}$ & $\begin{array}{l}\text { Driven by complex and urgent } \\
\text { problems. } \\
\text { - } \text { Questions and reflection. } \\
\text { Appropriate mindset, value, and } \\
\text { attitude of action learning members. }\end{array}$ \\
\hline $\begin{array}{l}\text { Occurrence } \\
\text { of Learning }\end{array}$ & $\begin{array}{l}\text { Reflection demonstrated in the sharing } \\
\text { of experience that forms the core of } \\
\text { knowledge base and an integral part of } \\
\text { meeting structure. } \\
\text { - Integration of learning into work } \\
\text { practices and workplace applications. }\end{array}$ & $\begin{array}{l}\text { - Solutions presented at the right } \\
\text { level of influence and authority for } \\
\text { appropriate action taking. } \\
\text { - Integration of learning into action } \\
\text { learning projects. }\end{array}$ \\
\hline $\begin{array}{l}\text { Member } \\
\text { Roles }\end{array}$ & $\begin{array}{l}\text { Facilitated by a coordinator to draw out } \\
\text { key learning experiences of members. } \\
\text { Cross-generational groupings of } \\
\text { volunteers to maximize knowledge } \\
\text { transfer in an organizational development } \\
\text { context. }\end{array}$ & $\begin{array}{l}\text { Facilitation of discussion by a set } \\
\text { advisor or coach. } \\
\text { - Diversity of action learning teams. } \\
\text { Commitment of top leadership to the } \\
\text { use of action learning. } \\
\text { - Support of a problem sponsor. }\end{array}$ \\
\hline
\end{tabular}

Table 1: Comparison between Team-Based Knowledge Sharing and Action Learning

In summary, we present a comparison between the team-based knowledge sharing framework and action learning in Table 1 (adapted from Yeo and Marquardt, 2015). Although the two learning processes appear similar, there are some fundamental differences. For instance, knowledge sharing in Saudi Aramco is driven by volunteer teams not particularly supported by a problem sponsor as found in action learning teams. A key feature of the team-based knowledge sharing framework is that team composition is largely based on cross-generational groupings to ensure optimal knowledge transfer between employees in meeting job-specific needs. In contrast, action learning teams largely involve project or work teams that seek direct solutions for addressing complex and urgent problems critical to the problem sponsors. A more salient difference between the two processes is the potential outcome of team learning. While the Saudi Aramco framework focuses on the integration of learning into daily work practices and workplace applications, action 
learning aims to develop specific solutions that meet particular organizational needs. Despite the differences, both learning processes are problem-driven and aim to promote collaborative inquiry through deep questioning, double-loop feedback, and critical reflection.

\section{Practical Dimension of the Framework}

In this section, we further explicate the practical dimension of the Saudi Aramco knowledge sharing framework (Fig. 1) by describing the significance of each phase: input, process, and output.

\section{Prior learning: Input}

A challenge statement is motivated by a work-related issue which serves as a stimulus for change. Often framed as a question, it captures the focal points of the problem complexity, allowing team members the scope to interpret the problem and uncover commonalities and differences in their thinking and perception of the problem. It promotes inquiry rather than mere discussion and moves the team towards shared understanding. It is chosen collectively by team members prior to the knowledge sharing session. As members begin to interpret the challenge statement, they engage in a deeper level of understanding of the issues involved. In Saudi Aramco, the challenge statements often revolve around issues such as work processes, team cohesiveness, interpersonal communication, customer relations, learning strategies, and change management. These issues affect task interdependence, formal and informal networks, as well as organizational routines and norms.

To address the varying facets of workplace challenges, statements are often constructed as twoor three-pronged questions. For example, "How can we plan and implement communications that will effectively engage our employees to ensure their buy-in on HR-related initiatives/ programmes?" formulates the question in such a way that participants are invited to not only share experiences regarding employee engagement, but also to consider how participants might best implement possible solutions. In this regard, challenge statements invite inquiry into both the conceptual and practical aspects of the topic.

Two further illustrations follow. The first is captured in the question "What is good customer service and how can we make it an effective and efficient tool for better performance and results?" and which invites sensemaking, as ideas and experience intersect, allowing members to formulate a loose idea of what "customer service" means to them as a community. In the question, each participant is also asked to consider how the emerging, collective idea of "customer service" could be leveraged to make the organization more impactful and productive in light of the diverse experience of the group. A second illustration is the question: "What techniques can we develop to help new hires absorb organizational culture and become more quickly integrated into their new working environment?" This statement addresses both a new hire's awareness of the corporate environment and its culture, but also assimilation into this culture. Such carefully constructed questions discourage simplistic, right/wrong analysis of the challenge and one another's related experience, and promotes a more holistic approach, whose focus is more on discovery than prescription.

\section{During learning: Process}

The core of the session is the sharing of concrete experiences specific to the challenge statement uncovering tacit knowledge. Narratives usually revolve around how individuals solve specific 
problems or make strategic decisions. In Saudi Aramco, team-based knowledge sharing is facilitated by a coordinator and supported by a scribe who captures the main ideas, which are based on specific experiences articulated through personal narratives and relate to a particular practice.

The facilitator further draws out deeper meanings and facilitates dialogue between members through questioning and feedback. The deeper meanings emerging from this dialogue reflect members understanding of the challenge statement and are then captured by the scribe on flipcharts or display screens as codified tacit knowledge to be deposited in a central repository for storage and wider access. Team members are also required to share a knowledge resource, particularly materials they have read and of relevance to the work challenge in question, such as journal articles, books, reports, brochures, and video links. Individual insights gleaned from such materials, when shared openly, will further serve as codified explicit knowledge as main ideas are also recorded on flipcharts or display screens and subsequently stored. Each team typically meets quarterly during office hours in their workplaces for about 90 minutes each.

\section{Post learning: Output}

The knowledge shared is subsequently experimented individually or collaboratively in practice. The transfer of knowledge to practice facilitates organizational change through work improvement processes. In Saudi Aramco, team members are encouraged to develop a workplace application as part of their learning outcomes. Collectively, the team works towards developing an action plan for implementation which will be endorsed and/or sponsored by senior management. Sponsorship refers to specific resources such as financial budget, training, and employee involvement which are factored in by the department for the implementation of any approved workplace applications. As more and more teams are established across the corporate framework, workplace applications addressing dominant organizational issues will also increase, providing recommendations for consideration of corporate-wide policies. This is one avenue for knowledge application to be institutionalized in order to benefit the wider community.

\section{Summary of team-based knowledge sharing}

Team-based knowledge sharing is a framework for connecting employees who wish to share, on a voluntary basis, their knowledge and experiences and seek to learn from the mistakes, challenges and strategies of others. In team-based knowledge sharing, participants share a common commitment to change and experimentation. Structured and process driven, the team interprets and reflects on a challenge statement relevant to its work and organization. The focus and emphasis of dialogue is the challenge statement, often a question commencing with the word "How". The statement or question focuses on improvement and not a particular problem. The acquired knowledge and experiences of the team members are used to change and/or sustain effective practice.

Team composition is crucial for the successful implementation of the framework. In Saudi Aramco, teams are established through cross-generational or cross-occupational groupings to ensure purposeful knowledge sharing for the bridging of particular knowledge gaps (Argote, Gruenfeld, and Naquin, 2001; Bechky, 2003). A striking feature in the Saudi Aramco teams is member roles, where knowledge sharing is facilitated by an individual, also the team coordinator, through questioning and feedback, drawing out critical lessons learned from all 
members. Although members of any knowledge sharing team could potentially change through time, there is some sustainability in key position holders such as team coordinator, scribe, and resource coordinator, who will in turn help ensure stabilization of team membership. Thoughtful facilitation through face-to-face dialogue and reflection leads participants to make sense of individual narratives shared before co-constructing a collective narrative to address a specific challenge statement (Weick, Sutcliffe, and Obstfeld, 2005). All output is valued, captured, and shared in a systemic way by the scribe and archived. Table 2 summarizes the specific features of team-based knowledge sharing in Saudi Aramco.

\begin{tabular}{|l|l|}
\hline Structure & \multicolumn{1}{c|}{ Key Characteristics } \\
\hline \multirow{3}{*}{ Input } & Sessions are driven by practical challenges rather than problems requiring solutions. \\
\cline { 2 - 3 } & Reflection is a key component of the session. \\
\hline \multirow{3}{*}{ Process } & Sessions are facilitated, not led, i.e. a trained facilitator is required. \\
\cline { 2 - 2 } & Sessions are based on a specific structure of learning. \\
\cline { 2 - 2 } & Professionals share experiences and knowledge around challenging issues. \\
\hline \multirow{2}{*}{ Output } & Team tests out new ideas in practice. \\
\cline { 2 - 2 } & Team has an infinite life with revolving topics to meet needs of employees. \\
\hline
\end{tabular}

Table 2: Characteristics of the Team-Based Knowledge Sharing Structure

\section{Team-Based Knowledge Sharing Implementation}

Developing team-based knowledge sharing is a dynamic process which involves a variety of employees in the organization. First, the team establishes contact with prospective business organizations within Saudi Aramco and invites key decision makers and their employees to attend a briefing session about the initiative. At the end of the session, an invitation is given for volunteers to form a knowledge sharing team including the appointment of primary position holders, including a scribe and a resource coordinator. As mentioned, the scribe captures the best practices and other knowledge and ideas that emanate from the discussion. The resource coordinator stores the scribe's notes as well as electronic copies of all resources in a shared folder, which serves as a repository of knowledge for the entire organization.

Second, the team coordinator receives formal facilitation training from the second author in order to understand the framework at a deep enough level to preserve its structure and format within the team going forward. Soon after the facilitator's training, the coordinator schedules the first meeting of the team. The second author, also the coach, attends all meetings and participates on various levels, but always takes detailed notes on the team coordinator's facilitation skills, and holds a review meeting to share detailed feedback with the coordinator in a spirit of continuous improvement.

Third, the entire process from manager's orientation to the first meeting can be as short as two weeks or as long as two months. Getting people together voluntarily outside their main work responsibilities is challenging and offers lessons in coordination and advanced communication strategies. But once the team has its first meeting and the facilitator is trained up, the value of learning is evident and the interest in knowledge sharing is usually very strong for the second meeting. Team members are excited about getting back to the safe place of open sharing which team-based knowledge sharing offers. 
During the implementation barriers and opportunities can be encountered. Most barriers are of a logistical nature such as finalizing meeting venues and schedules. Getting everyone together on a particular date and ensuring a majority attends the meeting requires finesse on the part of every team coordinator. However, employees are already aware of the importance of sharing their workplace ideas and experience. As employees retire, leaving critical roles to be filled, there is a need from within the organization for tacit knowledge to be shared so that undocumented expertise is passed on and preserved. With the concept of team-based knowledge sharing established and explained as a key HRD practice in Saudi Aramco, we turn now to the research question at the heart of this paper: "How is learning perceived as occurring through team-based knowledge sharing in Saudi Aramco?"

\section{Methodology}

We undertook a multi-pronged approach to gathering different sources of data through a variety of qualitative methods in order to address the research question. The aim was to explore the teams' direct and indirect experience of knowledge sharing as well as their learning and application both within and beyond the work context as perceived by the participants (Lincoln and Guba, 1985). The study was longitudinal in nature. We started gathering the data in 2012, culminating in a more formalized approach lasting nine months in 2015. Earlier data collection involved unobtrusive observations in knowledge sharing activities and informal conversations with participants. However, in 2015 we conducted an online survey which was distributed to over 120 members to capture qualitative feedback through open-ended questions, of which 57 complete responses were received.

We also conducted 22 interviews with members of 10 teams, each lasting on average 45 minutes. The sampling frame for the selection of interviewees was random with three boundary conditions, including gender, functional, and tenure distribution (Creswell, 1994) in order to ensure a crosssection of the employees in Saudi Aramco (and illustrated in Table 3). We were also careful to ensure that the interviewees represent a diverse mix of nationalities including Saudi Arabs, regional Arabs, and expatriates. We further observed and participated in 15 knowledge sharing sessions each lasting an average of 90 minutes capturing first-hand ethnographic data on team participation and learning dynamics. From a longitudinal perspective, we engaged in numerous informal conversations with various stakeholders such as employees, supervisors, and department managers to gain both internal and external views about team-based knowledge sharing.

\begin{tabular}{lcc}
\hline Job Function & Interviewee Code & (N=Interviews) \\
\hline Financial Accounting & R1-R3 & 3 \\
Professional Learning & R4-R7 & 4 \\
Academic Planning & R8-R9 & 2 \\
General Educational Partnerships & R10-R11 & 2 \\
Research and Development & R12-R15 & 4 \\
Human Resource Systems Support & R16-R18 & 3 \\
Power Systems Engineering & R19-R20 & 2 \\
Personnel Services & R21-R22 & 2 \\
\hline
\end{tabular}

Table 3: Interview Sample 
In tandem, the overall data was triangulated by a variety of supporting materials ranging from meeting minutes to internal documents such as reports, emails, and intranet information. The rich qualitative data underwent content analysis where emerging themes were identified through pattern matching of anecdotal accounts (Miles and Huberman, 1994). As part of the exploratory research, analytic rigor was of critical importance to us as we employed an ongoing comparative technique to help us make sense of the overall data through theoretical sampling (Glaser and Strauss, 1967).

In terms of coding, terms or phrases used by the informants were employed that gave rise to categories of meanings based on Miles and Huberman's (1984) categorization and thematicidentification techniques. The data were first coded using broad categories and more specific categories based on the interview questions including predetermined and improvised probes. The data was shared amongst the authors to eliminate potential coder biases. We first examined the raw data of the transcribed interviews as a team, gaining a sense of the overall meaning of the data. We then each made further sense of the messy data by identifying salient themes and patterns independently through the specific experiences of the informants (Guba and Lincoln, 1994). Because of our direct involvement in many of the teams, we were able to recognize the characteristics of team behaviour and potential learning occurrences based on their references to particular challenge statements, individual stories, and suggested action plans. We subsequently met as a team on several occasions to identify similarities and discrepancies of our interpretation of the data. Observational and archival data, at this point, served as confirmatory evidence for pattern matching based on salient themes (Patton, 2002). When these themes were interpreted by relating them back to the literature, we were able to develop an integrated perspective of data arriving at a clearer set of collective responses (Krippendorf, 1980). Overall, this iterative process between coder interpretations as well as primary and triangulated data helped us to identify and refine the conceptual patterns that offered significant insights into the research inquiry.

\section{Influences of Knowledge Sharing on Organizational Outcomes}

Team-based knowledge sharing has contributed to an increase in the knowledge capital of Saudi Aramco on an ongoing basis. Both the primary and triangulated data suggest five main areas of influence as a result of implementing the framework: developing competence, managing expectations, harmonizing silos, facilitating cultural change, transforming knowledge boundaries, and developing reflective practice. In particular, while the survey data gave rise to the identification of specific competencies and outcomes as a result of knowledge sharing, the interview data offered insights into HRD practices and contributed to the illustrations exemplified in this paper. The findings in response to the research question are next discussed.

\section{Developing competencies}

At the individual level, team members developed reflective listening skills in an environment that promotes people conversations. The respondents indicated that they were able to step back and listen to others and this helped them increase their self-awareness. They felt that they could influence others more effectively by internalizing the perspectives of others. In turn, they increased their identification of self in the context of diverse others, leading to better interpersonal relations and social competence. Such competence also led to better teamwork and collaborative efforts, 
evident in Saudi Aramco's cross-divisional knowledge sharing teams where cross-boundary functional ties were forged, as exemplified in the following interview extract:

This indeed is[a] new concept for me ... [A] useful platform is made available to exchange ideas ... [share] views and learn from [different] experiences. Analysis of the experiences could improve individual development. Confidence enhancement among team members ... [helps us to] accomplish tasks more professionally. (R15)

Our data also suggested the development of several other competencies as a result of teambased knowledge sharing. First, individuals engaged in wider and deeper sensemaking as they learned to interpret complex work-related issues while challenging their mental models through feedback and dialogue. Individuals also enhanced their communication skills as they learned to articulate their personal narratives at a level persuasive for all members to understand and appreciate. These narratives include not only past experiences but also lessons learned from organizationally-sponsored events such as seminars, workshops, and conferences. An informant recognized the need to develop communication skills through knowledge sharing:

Knowledge sharing has increased my understanding by considering how my message might be received by the other person. In addition, it helped me to communicate clearly to avoid misunderstandings and potential conflict with others. (R21)

Team facilitators developed more extensive communication abilities to aid them in their new leadership role. Personal visits to fellow participants, phone calls, and pre- and post-meeting emails built their capacity to engage others in collaboration.

Critical thinking skills were also developed when participants learned to engage in critical reflection and exchange insights that helped one another connect their past experience to the current context in responding to change. Moreover, many of the respondents indicated that teambased knowledge sharing had fostered their leadership potential when they learned to challenge assumptions through questioning and provide timely feedback to help one another make sense of the wider context of change. According to one team facilitator:

Knowledge sharing is an essential part of developing informed and connected leaders, and this initiative is an equal-voice forum within which anyone can respectfully challenge assumptions, question ideas, and contribute critical feedback to colleagues in an open, professional atmosphere. Change is inevitable, and a must — and it is all-inclusive opportunities like these knowledge sharing sessions that ensure that it is as positive and effective as possible. (R5)

More importantly, participants learned to develop a personal "voice" by projecting distinct perspectives about their professional practice, increasing their self-confidence. Additionally, some respondents reflected that they were exposed to greater change management skills as knowledge sharing offered them a psychologically-safe space to build trust and understanding through the testing of ideas leading to knowledge experimentation. They subsequently forged networks of learning and practice that enabled them to facilitate change more effectively. Finally, individuals indicated that they developed knowledge management skills when they learned to make sense of individual knowledge and experiences, and codify tacit knowledge as lessons learned; for example:

The scribe helps to organize and centralize the collective knowledge of the group - its shared information and resources - for the organization to refer to later. (R7) 
Participants learned to distil the essence of individual best practices and coproduce knowledge that mattered to the team for subsequent experimentation. Finally, being part of a knowledge sharing team increased individuals' networking skills as active participation helped develop cross-boundary learning beyond one's organizational unit or department. One facilitator stressed the impact of multicultural collaboration in networking with his knowledge sharing teammates:

The diversity of these people from all aspects, allowed me to accommodate a myriad of ideas and cultures while working with them. (R12)

Some members even extended the learning to their families and the wider community beyond the organization.

\section{Managing expectations}

At the individual level, team-based knowledge sharing helped members articulate and identify complex issues that confronted their work practices. Communication was found to be one of the critical challenges that prevented mutual understanding between employees in the organization. Experiences communicated through knowledge sharing not only helped individuals to question assumptions but also provide and receive feedback in order to avoid potential work conflict at the group level. The dynamics of questioning and feedback further helped them manage their expectations and focus on shared objectives that further built greater synergy through crossfunctional collaboration, as exemplified in the following extract:

Our last [knowledge sharing] meeting focused specifically on dealing with supervisor disagreements; and during a recent misunderstanding between me and my Unit Head, I was able to leverage some of the techniques that were discussed during the recent meeting such as trying to see things from my Unit Head's point of view while at same time maintaining a high level of professionalism. (R20)

\section{Harmonizing silos}

Team-based knowledge sharing promoted openness which raised the consciousness of individuals about the internal and external environment, helping them make better sense of their work context. They derived psychological safety by identifying common work-driven sentiments and relating individual narratives about particular work challenges. At the group and organizational level, knowledge sharing provided a conversational space for individuals of different functions to share specific experiences based on familiar or shared challenges. For instance, cross-divisional knowledge sharing teams served to bridge knowledge gaps between organizational units by capitalizing on shared resources to increase work efficiency:

The [knowledge sharing] session on dealing with stress helped me to realize that my own position has relatively little stress compared to the other attendees and that I shouldn't complain [about my situation]. That's more of an indirect benefit [of participation], but it was significant. (R4)

\section{Facilitating cultural change}

As knowledge sharing was more deeply embedded in the organization, the urgency for change in some specific work areas began to surface. At the individual level, sensemaking of contexts and experiences facilitated critical self-reflection. As teams formulated strategies for change through specific workplace applications, they sought collaboration by garnering support from both colleagues and management. As an example, a team in Saudi Aramco developed communication 
ground rules as a workplace application to improve interactional dynamics in their department due to a recent restructuring. Collaboration between the team and key stakeholders of the department helped them implement the application successfully. The shift from self to others created the condition for cognitive transition from individual to group reflection as team members discussed critical issues that ultimately affected the overall culture. Collectively, team-based knowledge sharing helped develop a culture of learning and innovation in Saudi Aramco, as exemplified in the following extract:

Very excited to continue attending those [knowledge sharing] sessions, and most importantly to see some changes in reality. I learned how important [it is] to share knowledge and talk to my colleagues to exchange opinions. (R17)

\section{Transforming knowledge boundaries}

Team-based knowledge sharing also helped bridge cross-generational knowledge gaps, particularly with the demographic shifts the organization is facing. In 2020, the organization's workforce will see an increase in Generation Y employees assuming key leadership positions. This potentially poses a challenge for the organization given the possibility of losing its intellectual capital through outgoing or retiring employees if an appropriate knowledge transfer strategy is not in place. Team-based knowledge sharing has therefore served as an HRD intervention to capture tacit knowledge of individuals and store it in codified form including specific lessons learned from best practices. Such lessons and practices could in turn be institutionalized at the wider level increasing organizational learning capacity, as suggested by the following respondent:

[Team-based] knowledge sharing made a great impact on me as a younger employee within the company. Working in a newly established department brings many worries/concerns to the younger generation and how to learn effectively. Having a knowledge sharing team and discussing business and communication related topics have added great value [to me]. Ideas shared could be used to help newly-joined employees or young professionals. (R10)

\section{Developing reflective practice}

At the operational level, the framework promoted reflective practice by raising the consciousness of individuals based on ongoing experience. Simply put, reflective practice promotes learningin-practice which suggests learning by doing and vice versa. The more frequent individuals learn to reflect on their actions, particularly how their actions can potentially make a difference to their work and social relations, the greater their learning in practice. Lessons learned from ongoing practices in turn create new actions that can enable or constrain structures of both task and social relations, as exemplified in the two extracts which follow:

This kind of [team-based] knowledge sharing is a two-way communication in which everyone is learning from others. The learning outcomes are maximized because we are learning from colleagues who are sharing with me the same work environment, business practices and management mentalities. (R3)

I have been sharing knowledge with fresh engineers in the unit and this received overwhelming acceptance. These engineers could be seen discussing issues among themselves and do take necessary support from us as required. This change was experienced by me in our unit among other engineers. (R19) 
At the strategic level, team-based knowledge sharing is positioned to develop critical change behaviours through the ATP aimed at identifying and institutionalizing best practices, as illustrated in Table 4. The company's four critical behaviours programme provides the means to achieve this. Already, team-based knowledge sharing has seen a macro-level influence on the organization's transformation strategy as found in an increase in collaborative initiatives between departments and a higher level of commitment of employees seeking change.

\begin{tabular}{|c|c|c|c|}
\hline $\begin{array}{l}\text { Critical } \\
\text { Behaviour }\end{array}$ & Description & $\begin{array}{l}\text { Knowledge Sharing } \\
\text { (Based on Practice) }\end{array}$ & $\begin{array}{l}\text { Outcomes } \\
\text { (Based on Data) }\end{array}$ \\
\hline Empowerment & $\begin{array}{l}\text { Give people } \\
\text { responsibility to } \\
\text { achieve results } \\
\text { and help them } \\
\text { overcome major } \\
\text { issues. }\end{array}$ & $\begin{array}{l}\text { Every member, regardless of rank, } \\
\text { is empowered to help determine } \\
\text { a specific challenge statement } \\
\text { directly related to pressing work } \\
\text { issues and share knowledge that } \\
\text { can make a real change in the } \\
\text { workplace. }\end{array}$ & $\begin{array}{l}\text { Knowledge sharing } \\
\text { has increased a sense } \\
\text { of responsibility at the } \\
\text { individual and group level to } \\
\text { take potential action for the } \\
\text { improvement of work life, } \\
\text { and provided an arena for } \\
\text { employees and managers to } \\
\text { share as equals. }\end{array}$ \\
\hline Conversations & $\begin{array}{l}\text { Communicate } \\
\text { expectations } \\
\text { and discuss } \\
\text { performance } \\
\text { and career path } \\
\text { participants on a } \\
\text { regular basis. }\end{array}$ & $\begin{array}{l}\text { The learning structure promotes } \\
\text { questioning, dialogue, and } \\
\text { feedback to draw out deeply- } \\
\text { held assumptions about issues } \\
\text { concerning daily work, Saudi } \\
\text { Aramco's } 2020 \text { vision, and career } \\
\text { prospects. }\end{array}$ & $\begin{array}{l}\text { Personal voice is a powerful } \\
\text { tool and has increased } \\
\text { individuals' self-confidence } \\
\text { and professional identity, } \\
\text { widening their network to } \\
\text { accomplish daily tasks. }\end{array}$ \\
\hline $\begin{array}{l}\text { Decision } \\
\text { Making }\end{array}$ & $\begin{array}{l}\text { Be disciplined } \\
\text { and explicit in } \\
\text { your strategic } \\
\text { and commercial } \\
\text { thinking for } \\
\text { important } \\
\text { business } \\
\text { decisions. }\end{array}$ & $\begin{array}{l}\text { Team learning helps members see } \\
\text { the bigger picture of their work } \\
\text { enabled through critical reflection } \\
\text { of individual experiences, which } \\
\text { in turn increases their capacity } \\
\text { to make appropriate decisions } \\
\text { surrounding their work. }\end{array}$ & $\begin{array}{l}\text { Seeing the bigger picture } \\
\text { has increased the learning } \\
\text { orientation of individuals to } \\
\text { engage in deeper dialogue } \\
\text { with management, leading } \\
\text { to bottom-up and lateral } \\
\text { decision making. }\end{array}$ \\
\hline Collaboration & $\begin{array}{l}\text { Commit to and } \\
\text { work towards } \\
\text { shared goals } \\
\text { with colleagues } \\
\text { across the } \\
\text { organization. }\end{array}$ & $\begin{array}{l}\text { Team-based knowledge sharing } \\
\text { offers a platform to bring disparate } \\
\text { teams together for sharing work- } \\
\text { induced knowledge, removing } \\
\text { functional silos and promoting } \\
\text { collaborative learning and action. }\end{array}$ & $\begin{array}{l}\text { Sharing of common issues } \\
\text { has increased individuals' } \\
\text { awareness of task } \\
\text { interdependence, leading } \\
\text { to a shared understanding } \\
\text { of professional roles and } \\
\text { organizational objectives. }\end{array}$ \\
\hline
\end{tabular}

Table 4: Influence of team-based knowledge sharing on critical change behaviours

\section{Implications for HRD Practice and Research}

This study offers several implications for HRD practice and research. The study extends current conceptualization of team learning based on the perspective of knowledge utilization. It suggests that team-based knowledge sharing promotes an interplay of learning, experience, and action that ultimately transforms practice and sustains effective practice (c.f. Antonacopoulou, 2006; 
Yeo and Marquardt, 2015). The framework introduced in Saudi Aramco provides a more focused and holistic learning experience for individuals rather than operating through loosely-coupled or less controlled networks of learning seen in informal knowledge sharing (Marsick and Watkins, 1990). The following are important implications for HRD according to the three main phases of team-based knowledge (Fig. 1): input, process, and output; each phase aiming to promote specific learning processes occurring in team settings.

\section{Input: Connecting}

Interpretation of work-related challenges develops reflexive learning as individuals socially construct meanings around a working theory that contributes to work practice (Cotter and Cullen, 2012). To be reflexive is to engage in a much deeper level of reflection (Cunliffe, 2004). Collective interpretation of shared workplace issues induces critical reflection through a deeper sensemaking of prior, lived, and projective realities (Weick, Sutcliffe, and Obstfeld, 2005), connecting learning and practice in mutually-constitutive ways (Schön, 1983). Such interpretative process allows individuals to cognitively experience different contexts as they exchange accounts of the symbolic, social, and material aspects of their specific work practices (Niewolny and Wilson, 2009). Interpretive accounts further help them develop frames of references that connect their roles and actions to the wider context of work, offering a different dimension of individual learning (Watkins, 2000).

\section{Process: Internalizing}

The sharing of concrete experiences takes the social construction of learning further as individuals negotiate deeper meanings by demonstrating their intuitive responses to specific narratives (Plaskoff, 2011; Torraco, 1999). The articulation of embedded and situated practice helps bring tacit knowledge to the forefront as individuals relate particular actions to specific experiences through a language that resonates with others (Brown, Collins, and Duguid, 1989). Situated practice is a process of learning where an appropriate action is enacted at a particular point in time, similar to an act-in-moment (Brown and Duguid, 1991). A heightened awareness of learning often occurs in moments like these, which will lead to learning-in-practice. This is when learning occurs in action and action in learning (Antonacopoulou, 2006); a more constitutive form of learning by doing. Knowledge generated from situated practice is often a by-product of internalizing — that is, learning of routines and practices including the influence of emotions, power, and politics on social relations (Lave, 1998; Vince, 1996).

As individuals engage in learning-in-practice, they integrate formal (commonly-accepted) and intuitive (localized) knowledge by identifying dominant action patterns as individual "best practices" (Antonacopoulou, 2005). Localized knowledge reflects learning that has been accumulated over a certain period in a particular context unique to the practitioner (Yanow, 2004). Team learning further promotes the collaborative crafting of "best practices", converting abstract conceptualization into potential value for active experimentation (Gold and Smith, 2003; Kolb, 1984). Through questioning and feedback, double-loop learning is developed to achieve shared understanding. Double-loop learning usually occurs at a deeper level of dialogue where individuals engage in feedback loops to make sense of complex phenomena (Argyris, 1982; Knapp, 2010). As mentioned, double-loop feedback occurs at the intersection between the sharing of stories and consolidation of ideas (see Fig. 1). At this point, feedback plays a critical role in helping individuals translate specific experiences into recognized knowledge (Sole 
and Edmondson, 2002). By engaging in feedback, individuals learn to reframe their cognitive schemas by changing the trajectory of learning which in turn increases their reflective inquiry (Goodman and Wood, 2004).

\section{Output: Externalizing}

A primary outcome of team-based knowledge sharing is the individual and collective experimentation of various "best practices" arising from the narratives shared. This is where individuals take their learning further into action in a cyclical manner constituting practice (Raelin, 2007). Through a continuous cycle of reflection, the structure of actions will take greater shape in practice increasing individuals' awareness of the learning dynamics. Such awareness helps them determine if the dynamics will enable or constrain subsequent actions (Marquardt, 2004). As individuals engage in learning-in-practice, they externalize their learning by becoming reflective practitioners (Schön, 1983). This is when they transform the state of knowing (awareness of what is going on) to becoming (enactment of awareness in action) (Coghlan, 2003). Of becoming further suggests that individuals learn to modify their actions to make a difference to their social context (Tsoukas and Vladimirou, 2001). The translation of "knowing" to "becoming" occurs at the intersection between "idea experimentation" and "translation into best practices" of the framework (Fig. 1) where individuals gain confidence in the knowledge they share and the outcomes developed through their actions. Ultimately, the structured approach to knowledge sharing helps generate collective interest in validating knowledge that matters to them as a team. Collective actions developed through collaborative experimentation subsequently shape work practices and transform learning at the organizational level (Coghlan and Coughlan, 2015; Fenwick, 2008). Through team-based knowledge sharing, learning therefore becomes an inescapable way of organizational life (Senge, 1990).

In sum, team-based knowledge sharing has led to some direct and indirect influences of organizational learning and change since its inception. With a pressing need for wider knowledge sharing, Saudi Aramco is placing a strategic focus on team-based knowledge sharing by helping employees transform themselves through critical change behaviours shaping organizational culture (see Fig. 2). Such behaviours support the company's strategic intent, which aims to make the company more agile and better equipped to navigate the challenges of the future economic landscape.

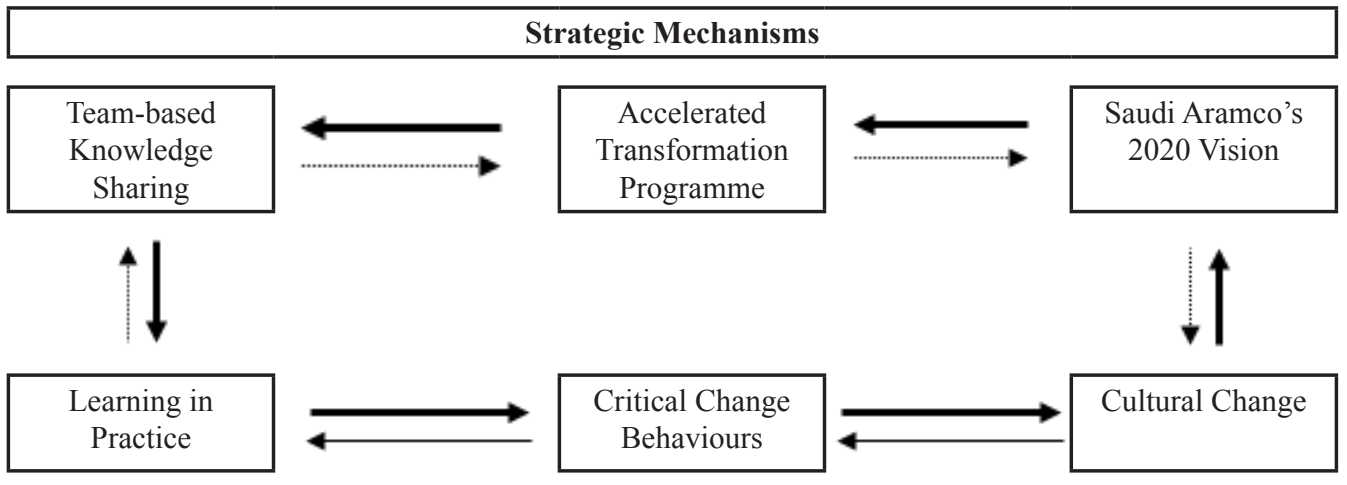

Operational Mechanisms

Fig. 2: A strategic perspective of team-based knowledge sharing 


\section{Conclusion}

In this paper, we have discussed team-based knowledge sharing as not merely an activity but rather an HRD process that unlocks individual tacit knowledge through the sharing of personal narratives that are constructed in response to commonly-shared complex work challenges. Such narratives, albeit unique, facilitate questioning and feedback as individuals seek clarification regarding each other's frames of references. Articulation of individual "best practices" encourages others to engage in narrative coproduction in order to shape specific lessons learned for subsequent experimentation. Although team-based knowledge sharing is similar to action learning from the conceptual perspective, it operates quite differently than action learning. The study reported upon in this paper suggests that membership stability and continuity contribute towards a greater commitment of individuals to team learning. Further, problem-driven knowledge sharing engages team members in seeking collaborative solutions to improve work situations by increasing their propensity for knowledge experimentation. Workplace applications are a by-product of action modifications as members develop alternative solutions to address specific work-related challenges. Consequently, team learning is facilitated through knowledge sharing and experimentation.

The study is not without its limitations. It is focused on a framework that is applicable in one organization in Saudi Arabia where a wider application would have been useful. Although the framework was first implemented in Singapore (see Yeo, 2006), it could have served as a comparative backdrop to shed some light on the variation of its utilization and implications in a different context. Still, this study has yielded some valuable insights into the importance of knowledge sharing in relation to team learning. The efficacy of the framework not only lies in the structure but also its application in wider contexts influencing the way individuals think, feel, and act.

To advance this study, it would be useful to consider if team composition has specific influences on team learning outcomes. For instance, researchers could explore if homogeneous and heterogeneous teams learn differently in structured knowledge sharing processes (c.f. O'Leary, Mortensen, and Woolley, 2011). Researchers could also examine if problem complexity might offer different cognitive triggers that influence the trajectory of team learning. In particular, team members might recognize the complexity of a problem but might not want to take any ownership of it. As such, the tension between problem complexity and ownership might offer new insights into the way teams learn (c.f. Yeo and Marquardt, 2015). Finally, researchers could explore if the role of facilitator is a critical agent of change in team learning contexts. For instance, facilitator characteristics such as personality, seniority, professional background, communicative aptitude, and experience might affect team learning dynamics differently (c.f. Sarin and McDermott, 2003).

To conclude, this HRD initiative has been a transformative learning experience for many employees, enhancing their professional identity as they critically reflect on their roles, task interdependence, and shared resources (Mezirow, 2009). In turn, knowledge sharing governed by common objectives will inadvertently lead to interventions at the organizational level transforming practice. Moving forward, the organic growth of team-based knowledge sharing in Saudi Aramco will not only create dramatic shifts in its intellectual landscape but also enable change behaviours that fuel the engine of its accelerated transformation programme towards realizing its 2020 vision. 


\section{References}

Antonacopoulou, E. P. (2005). Learning, working and living: An introduction. In E. P. Antonacopoulou, P. Jarvis, V. Andersen, B. Elkjaer, and S. Hoyrup (Eds.), C (pp. 1-15). Basingstoke, UK: Palgrave Macmillan.

Antonacopoulou, E. P. (2006). Working life learning: Learning-in-practise. In E. P. Antonacopoulou, P. Jarvis, V. Andersen, B. Elkjaer, and S. Hoeyrup (Eds.), Learning, working and living: Mapping the terrain of working life learning (pp. 234-254). London: Palgrave.

Argote, L. (1999). Organizational learning: Creating, retaining, and transferring knowledge. Boston, MA, Kluwer Academic Publishers.

Argote, L., Gruenfeld, D., and Naquin, C. (2001). Groups in learning organizations. In M. E. Turner (Ed.), Groups at work: Theory and research (pp. 369-411). Mahwah, NJ: Erlbaum.

Argyris, C. (1982). Reason, learning and action. San Francisco, CA: Jossey-Bass.

Bechky, B. A. (2003). Sharing meaning across occupational communities: The transformation of understanding on a production floor. Organization Science, 14(3), 312-330.

Bresman, H., and Zellmer-Bruhn, M. (2013). The structural context of team learning: Effects of organizational and team structure on internal and external learning. Organization Science, 24(4), 1120-1139.

Brown, J. S., Collins, A., and Duguid, P. (1989). Situated cognition and the culture of learning. Educational Researcher, 18(1), 32-42.

Brown, J. S., and Duguid, P. (1991). Organizational learning and communities-of-practice: Toward a unified view of working, learning and innovation. Organization Science, 2(1), 40-57.

Coghlan, D. (2003). Practitioner research for organizational knowledge mechanistic- and organisticoriented approaches to insider action research. Management Learning, 34(4), 451-463.

Coghlan, D., and Coughlan, P. (2015). Effecting change and learning in networks through network action. Journal of Applied Behavioral Science, 51(3), 375-400.

Cotter, R. J., and Cullen, J. G. (2012). Reflexive management learning: An integrative review and a conceptual typology. Human Resource Development Review, 11(2), 227-253.

Creswell, J. W. (1994). Research design: Qualitative and quantitative approaches. Thousand Oaks, CA, Sage.

Cunliffe, A. L. (2004). On becoming a critically reflexive practitioner. Journal of Management Education, 28(4), 407-426.

Cunningham, I. (2003). Reg Revans - an appreciation: The life of a learning guru. Development and Learning in Organizations, 17(3), 4-6.

Edmondson, A. C. (2002). The local and variegated nature of learning in organizations: A group-level perspective. Organization Science, 13(2), 128-146.

Edmondson, A. C., Dillon, J. R., and Roloff, K. S. (2008). Three perspectives on team learning: Outcome improvement, task mastery, and group process, Academy of Management Annals, 1(1), 269-314.

Fenwick, T. (2008). Understanding relations of individual - Collective learning in work: A review of research. Management Learning, 39(3), 227-243.

Fiol, C. M., and Lyles, M. A. (1985). Organizational learning. Academy of Management. Academy of Management Review, 10(4), 803-813.

Fox, S. (1997). Situated learning theory versus traditional cognitive learning theory: Why management educations should not ignore management learning. Systemic Practice and Action Research, 10(6), 727-747.

Glaser, B., and Strauss, A. (1967). Discovering grounded theory. Chicago, IL: Aldine.

Gold, J., and Smith, V. (2003). Advances towards a learning movement: Translations at work. Human Resource Development International, 6(2), 139-152.

Goodman, J. S., and Wood, R. E. (2004). Feedback specificity, learning opportunities, and learning. Journal of Applied Psychology, 89(5), 809-821.

Guba, E. G., and Lincoln, Y. S. (1994). Competing paradigms in qualitative research. In: N. Denzin, and Y. Lincoln (Eds.), Handbook of qualitative research (pp. 105-117). Thousand Oaks, CA, Sage. 
Hackman, J. R. (1987). The design of work teams. In: J. W. Lorsch (Ed.), Handbook of organizational behaviour (pp. 315-342). Englewood Cliffs, NJ: Prentice Hall.

Knapp, R. (2010). Collective (team) learning process models: A conceptual review. Human Resource Development Review, 9(3) 285-299.

Kolb, D. A. (1984). Experiential learning: Experience as the source of learning and development. New Jersey, NJ: Prentice-Hall.

Krippendorff, K. (1980). Content analysis: An introduction to its methodology. London: Sage.

Lave, J. (1988). Cognition in practice: Mind, mathematics, and culture in everyday life. Cambridge, UK: Cambridge University Press.

Lincoln, Y. S., and Guba, E. G. (1985). Naturalistic inquiry. Beverly Hills, CA: Sage.

Marquardt, M. J. (2004). Optimizing the power of action learning. Palo Alto, CA: Davies-Black.

Marquardt, M. J. (2011). Optimizing the power of action learning: Real-time strategies for developing leaders, building teams, and transforming organizations (2nd Ed.). Boston, MA: Nicholas Brealey Publishing.

Marsick, V. J., and Watkins, K. E. (1990). Informal and incidental learning in the workplace. New York, NY, Routledge \& Kegan Paul.

Mezirow, J. (1990). Fostering critical reflection, San Francisco, CA: Jossey Bass.

Mezirow, J. (2009). Transformative learning theory. In J. Mezirow, E. Taylor, and Associates (Eds.), Transformative learning in practice: Insights from community, workplace and higher education (pp. 18-31). San Francisco, CA: Jossey-Bass.

Miles, M. B., and Huberman, A. M. (1994). Qualitative data analysis. Thousand Oaks, CA, Sage.

Niewolny, K. L., and Wilson, A. L. (2009). What happened to the promise? A critical (re)orientation of two sociocultural learning traditions. Adult Education Quarterly, 60(1), 26-45.

O'Leary, M. B., Mortensen, M., and Woolley, A. W. (2011). Multiple team membership: A theoretical model of its effects on productivity and learning for individuals and teams. Academy of Management Review, 36(3), 461-478.

Patton, M. Q. (2002). Qualitative research and evaluation methods (3rd Ed.). Thousand Oaks, CA: Sage.

Plaskoff, J. (2011). Intersubjectivity and community-building: Learning to learn organizationally. In M. Easterby-Smith and M. Lyles, (Eds.), Wiley handbook of organizational learning and knowledge management (pp. 199-223). Chichester, UK: Wiley.

Raelin, J. A. (2007). Toward an epistemology of practice. Academy of Management Learning \& Education, 6(4), 495-519.

Ren, Y., Carley, K. M., and Argote, L. (2006). The contingent effects of transactive memory: When is it more beneficial to know what others know? Management Science, 52(5), 671-682.

Revans, R. W. (1982). The origin and growth of action learning. Brickley: Chartwell-Bratt.

Sarin, S., and McDermott, C. (2003). The effect of team leader characteristics on learning, knowledge application, and performance of cross-functional new product development teams. Decision Sciences, 34(4), 707-739.

Schippers, M., Edmondson, C. A. C., and West, M. A. (2014). Team reflexivity as an antidote to team information processing failures. Small Group Research, 45(6), 731-769.

Schön, D. (1983) The reflective practitioner. New York, NY: Basic Books.

Senge, P. (1990). The fifth discipline: The art and practice of the learning organization. New York, NY: Doubleday.

Simpson, P., French, R., and Vince, R. (2000). The upside of the downside: How utilizing defensive dynamics can support learning in groups. Management Learning, 31(4), 457-470.

Sole, D., and Edmondson, A. C. (2002). Situated knowledge and learning in dispersed teams. British Journal of Management, 13(S2), S17-S34.

Torraco, R. J. (1999). Integrating learning with working: A reconception of the role of workplace learning. Human Resource Development Quarterly, 10(3), 249-270.

Tsoukas, H., and Vladimirou, E. (2001). What is organizational knowledge? Journal of Management Studies, 38(7), 973-993.

Vince, R. (1996). Experiential management education as the practice of change. In R. French and C. Grey, (Eds.), Rethinking management education (pp. 111-131). London: Sage. 
Watkins, K. (2000). Aims, roles and structures for human resource development. Advances in Developing Human Resources, 2(3), 54-59.

Weick, K. (1995). Sensemaking in organizations. Thousand Oaks, CA: Sage.

Weick, K. E., Sutcliffe, K. M., and Obstfeld, D. (2005). Organizing and the process of sensemaking. Organization Science, 16(4), 409-421.

Yanow, D. (2004). Translating local knowledge at organizational peripheries. British Journal of Management, 15(1), 9-25.

Yeo, R. K. (2006). Learning institution to learning organization: Kudos to reflective practitioners. Journal of European Industrial Training, 30(5), 396-419.

Yeo, R. K., and Marquardt, M. J. (2015). (Re)Interpreting action, learning, and experience: Integrating action learning and experiential learning for HRD. Human Resource Development Quarterly, 26(1), 81-107.

\section{The Authors}

Roland K. Yeo is Management Learning Researcher at Saudi Aramco. He is also an Adjunct Senior Research Fellow with the University of South Australia Business School and teaches on the EMBA (AACSB) programme at the King Fahd University of Petroleum \& Minerals in Saudi Arabia as an Adjunct Associate Professor of Management. He holds a Ph.D. in Organization Studies from the Leeds Business School in UK. He is currently conducting practice-based research in areas relating to team learning, knowledge utilization, and sensemaking.

John R. Stubbs is Knowledge Officer at Saudi Aramco, where he serves as a consultant to departments across the company regarding the implementation of team-based knowledge sharing. He holds an MBA from Hong Kong University of Science and Technology and an MA from Columbia University. His interests include the success factors of diverse workplace cultures and the impact of facilitation in knowledge sharing.

Martin J. Barrett is a Management and Professional Trainer in Saudi Aramco's Training and Development Organization. He is Supervisor of the Professional Learning and Development Unit responsible for overseeing the delivery of the corporate on-boarding program known as the Saudi Aramco Professional Development Academy. Martin holds a Master's in Business Administration from the University of Hull and has a keen interest in the development of young professionals, organization development, and knowledge sharing.

\section{Acknowledgements}

The authors would like to acknowledge the support provided by Saudi Aramco for the development of the team-based knowledge sharing initiative, which resulted in this study. Also it should be noted that this initiative was recognized with a 2015 Global HRD Best Practice Merit Award by the International Federation of Training and Development Organizations (IFTDO). 